\title{
Flexural behaviour of externally prestressed beams. Part I: Analytical model
}

\author{
Chee Khoon $\mathrm{Ng}^{\mathrm{a}, *}$, Kiang Hwee Tan ${ }^{\mathrm{b}}$ \\ a Faculty of Engineering, Universiti Malaysia Sarawak, 94300 Kota Samarahan, Sarawak, Malaysia \\ ${ }^{\mathrm{b}}$ Department of Civil Engineering, National University of Singapore, Blk E1A, \#07-03, 1 Engineering Drive 2, Singapore 117576, Singapore
}

Received 13 January 2005; received in revised form 1 September 2005; accepted 20 September 2005

Available online 24 October 2005

\begin{abstract}
Two features that distinguish an externally prestressed beam from an otherwise internally bonded, prestressed beam are: (i) the tendon stress depends on the overall deformation of the beam; and (ii) the tendons are free to move relative to the section depth, resulting in eccentricity variations defined as second-order effects. This paper presents a simple "pseudo-section analysis" method which accounts for second-order effects in simply supported, externally prestressed beams subjected to two symmetrically applied concentrated loads. The proposed method predicts the load-deflection curve and provides explicit expressions for the tendon stress, which can be used to evaluate the moment capacity of the beam by section analysis based on the bond reduction coefficient in strain compatibility.

(c) 2005 Elsevier Ltd. All rights reserved.
\end{abstract}

Keywords: Analysis; Beam; External prestressing; Flexure; Strength; Second-order effects

\section{Introduction}

External prestressing refers to a post-tensioning method in which the tendons are placed on the outside of a structural element to facilitate flexural resistance. It may be efficiently utilized in the construction of segmental box-girder bridges as well as in the strengthening of existing concrete beams [1,2]. However, there has been relatively little documentation on the analysis and design of externally prestressed structures [3].

One of the reasons which leads to the complexity in the analysis of externally prestressed beams can be attributed to the eccentricity variations of external tendons under load, commonly referred to as second-order effects. That is, under the application of external loads, a concrete beam deforms with a nonlinear profile while the external tendons remain rectilinear in between anchorages and/or deviators, as shown in Fig. 1(a). This results in a relative movement of the external tendons with respect to the centroid of the concrete section in between the anchorages and/or deviators, as a result of which the flexural capacity of the beam is reduced [4-9].

Fig. 1(b) shows two schematic load-deflection curves of an externally prestressed beam. The solid line represents the

\footnotetext{
* Corresponding author. Tel.: +60 82 670525; fax: +60 82672317.

E-mail address: ckng@ feng.unimas.my (C.K. Ng).
}

load-deflection curve of the beam where second-order effects are neglected. If second-order effects are taken into account, the stiffness of the beam is reduced and the ultimate strength is relatively lower as shown by the dashed line. Mutsuyoshi et al. [7] tested a series of externally prestressed beams with a spanto-depth ratio of about 21 and reported that the reduction in beam strength due to second-order effects can be as high as $16 \%$. In another theoretical study by Alkhairi and Naaman [5], the eccentricity variation was reported to be more significant in beams with span-to-depth ratios greater than 24 and strength reduction as high as $25 \%$ can be observed for beams with a span-to-depth ratio of 45 .

Several investigators $[5-8,10]$ have attempted to consider the variation of eccentricity in their models for the analysis of externally prestressed beams. Typically, the effective tendon eccentricity at any location was related to the deflections of the adjacent deviators. By dividing the beams into finite sections and considering compatibility of member deformation and equilibrium of forces and moments, the total elongation of the external tendons for an applied load can be taken as the integral of the concrete strains at the level of the tendon. Of the available models, Alkhairi and Naaman's model [5] distinguishes itself from the others in that it considers an additional moment induced by shear. On the other hand, Mutsuyoshi et al. [7] have developed prediction equations based 